\title{
A photographic method for the measurement of motility of bull spermatozoa
}

\author{
S. G. Revell and P. D. P. Wood \\ Milk Marketing Board, Thames Ditton, Surrey KT7 OEL, U.K.
}

\begin{abstract}
Summary. Bull spermatozoa were diluted in skim milk-egg yolk and frozen. After thawing, the samples were added to citrate buffer and photographed (1 sec exposure, 400 ASA, dark field) to identify the tracks of the moving spermatozoa.

The proportions of motile spermatozoa in 1707 photographs of semen samples from 25 ejaculates were distributed binomially, and allowed motility to be estimated at a predictable level of precision, and without bias when one photograph from each of two straws was taken at random from an ejaculate. The variance was equal to its expectation and inversely proportional to the total number of spermatozoa in each photographic field.
\end{abstract}

\section{Introduction}

Economic use of semen in artificial insemination (A.I.) programmes demands an accurate estimate of sperm motility. In a suspension of other inert material, the movement of spermatozoa, which inhibits direct assessment, may be stopped by photography, and the moving spermatozoa can be identified by their tracks on the film. The use of dark field photomicrography for the study of sperm motility was first reported by Rothschild (1953). The technique has since been confined mostly to research laboratories, an exception being its use in quality control by an A.I. organization in the U.S.A. (Elliott, Sherman, Elliot \& Sullivan, 1973). The method described by Elliott et al. (1973) depends upon the diluting medium being of reasonable optical clarity. In this paper, we report a method for the photographic assessment of the motility of semen which has been diluted in an optically dense medium, consisting largely of U.H.T. (pasteurized at 'ultra high temperature') skim milk and egg yolk.

\section{Materials and Methods}

\section{Methods}

Bull semen was collected by using an artificial vagina and diluted to give a dose of $20 \times 10^{6}$ spermatozoa $/ 0.25 \mathrm{ml}$. The diluent consisted of $83 \%$ U.H.T. skim milk, $10 \%$ egg yolk and $7 \%$ glycerol (by volume), $1.25 \mathrm{~g}$ fructose $/ 100 \mathrm{ml}$ and penicillin and streptomycin, each at $500 \mathrm{i} . \mathrm{u} . / \mathrm{ml}$. The diluted semen was packed in $0.25 \mathrm{ml}$ French straws, equilibrated for $6 \mathrm{~h}$ at $5^{\circ} \mathrm{C}$, frozen in liquid nitrogen vapour, and stored in liquid nitrogen until required.

The laboratory equipment consisted of a Zeiss photomicroscope enclosed in a heated box, a water bath and a photographic dish-warmer: all were maintained at $35^{\circ} \mathrm{C}$. Clean glass slides and $22 \mathrm{~mm}$ diameter coverslips were warmed on the dish-warmer. A citrate buffer solution, consisting of $3.2 \%$ sodium citrate and $0.05 \%$ citric acid was prepared, $0.75 \mathrm{ml}$ aliquots were placed in small test tubes, and warmed in the water bath.

Straws of semen were thawed in the water bath, and the contents of each were added to a test tube containing the citrate buffer and mixed gently. After approximately $1 \mathrm{~min}$, a $10 \mu \mathrm{ldrop}$ was removed following further mixing, transferred to a warm slide and covered. Photographs were taken within 10 min of preparation, using dark-field illumination, a $1 \mathrm{sec}$ exposure, and Ilford HP4 film (ASA 400) at a magnification of $\times 64$. 
Moving spermatozoa in citrate buffer normally rotate and because the sperm head is spatulate each rotation can be seen as two flashes in a dark field. This produces 'tracks' on the film (Plate 1). Nonmotile spermatozoa are recognizable with little difficulty although a few heads will be edge-on to the observer.

The 'recovery rate' was calculated by counting the number of non-motile cells and the number of motile cells within the picture at the start of the exposure. The number of motile cells, obtained from the sum of all the tracks completely within the picture and half the number of tracks crossing the border, was then expressed as a percentage of the total sperm count. To reduce both the time required and the processing costs, the film was not printed. The counts were made by projecting the developed film onto matt white paper on a laboratory bench in a darkened room by means of a photographic enlarger. If required, the average velocity of the motile population could be calculated from the photograph by the method of Katz \& Dott (1975).

\section{Experiments}

Four experiments were performed to establish the consistency of the photometric technique, two in the summer and two in the winter of 1976. Methods of loading the straws into the freezing tank were examined for another purpose, and the results have been combined for the present analysis. In the four trials, 25 ejaculates from 10 bulls were used and 610 straws were sampled, by examination of 2 (123 straws) or 3 ( 487 straws) frames of film per straw. Each frame contained about 60 spermatozoa from which the percentage motile could be calculated.

\section{Results}

The percentage values were converted to the arcsine transform (Bartlett, 1937) and analysed as a hierarchy (Table 1).

Table 1. Analysis of variance of transformed percentages of motile spermatozoa estimated from photographic frames

\begin{tabular}{lrcc}
\hline \multicolumn{1}{c}{ Source of variation } & d.f. & Mean Square & Significance \\
\hline Between ejaculates within & & & \\
$\quad$ experiments & 54 & 769 & $P<0.001$ \\
Between straws per ejaculate & 496 & 39 & $P<0.001$ \\
Between frames per straw & 1097 & 12 & N.S. \\
\hline
\end{tabular}

The mean squares due to the experimental design, associated with 59 d.f., have been omitted.

The weighted mean number of spermatozoa per frame was 61.42 leading to an expected error variance of 13.35 on the assumption that the original data were random samples from a binomial distribution of percentages. Since the error variance in Table 1 was 12.3 and not significantly different from its expectation, the photographic result may be regarded as a best unbiased estimator of the percentage of motile spermatozoa in the frame. The four experiments gave error variances of $14,13,12$ and 8 , suggesting that the repeatability of the technique was good. There was significant variation among straws within ejaculates, indicating that a single straw may give a biased estimate of the recovery rate of the ejaculate from which it was drawn. The component of variance due to straws, however, was also close to 12 units, so that the variance of a single frame from a single straw was 24 units. Therefore the recovery rate of the whole ejaculate could be estimated more precisely by using a few frames from many straws than by using many frames from a few straws (Table 2). 

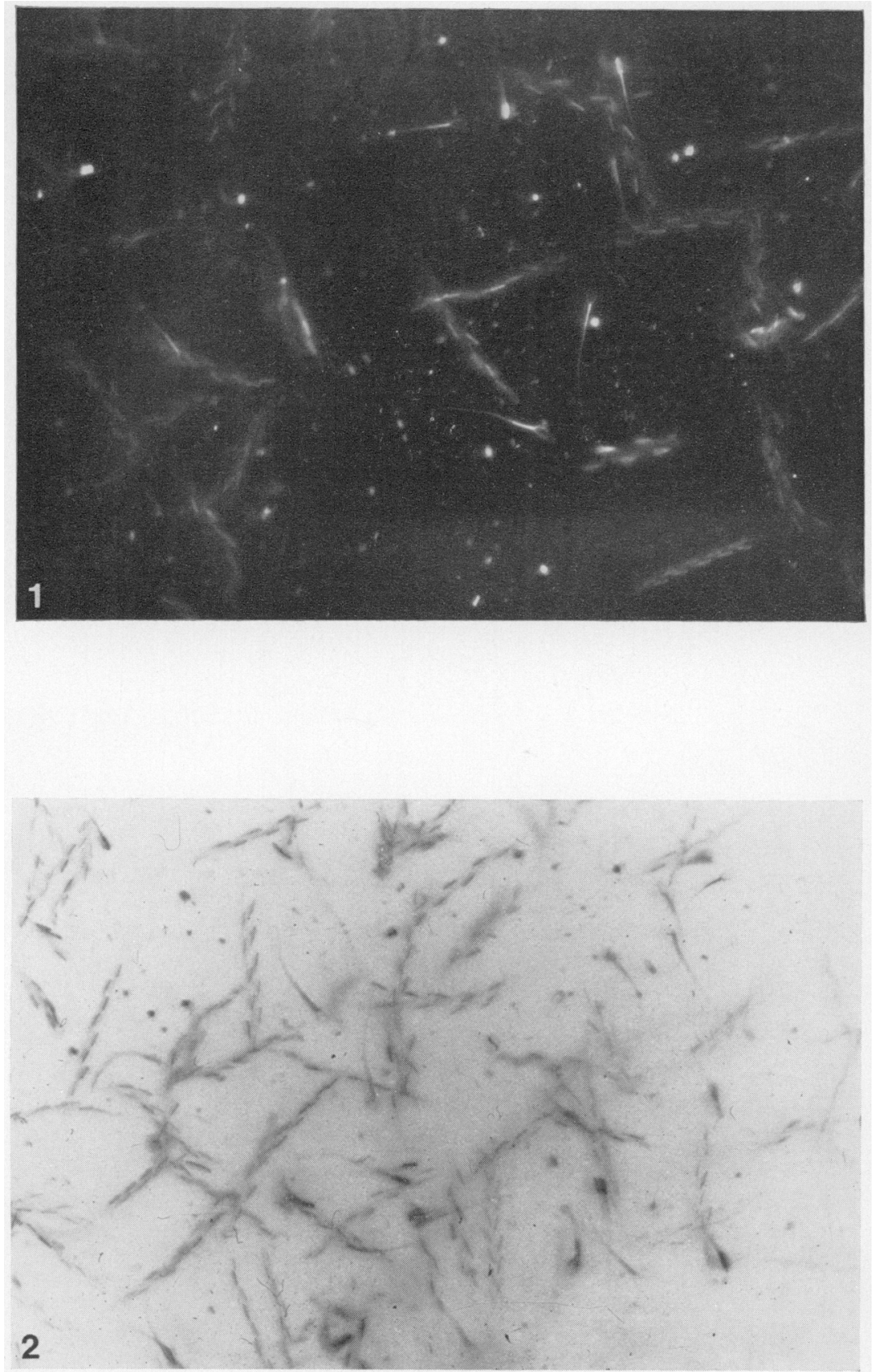

The tracks of bull spermatozoa moving in a citate butfer medium prepared after freezing and thawing. Non-motile spermatozoa make no trachs. (1) Image seen through the microscope: 12) Image of the projected negative. $\times 200$. 
Table 2. Confidence limits to the precision with which motility rates of spermatozoa can be estimated from pairs of straws

\begin{tabular}{|c|c|c|}
\hline \multirow[b]{2}{*}{$\begin{array}{l}\text { No. of pairs } \\
\text { of straws }\end{array}$} & \multicolumn{2}{|c|}{$\begin{array}{l}90 \% \text { Confidence limits* for percentage } \\
\text { motile spermatozoa/ejaculate }\end{array}$} \\
\hline & $\begin{array}{l}\text { One frame per } \\
\text { straw ( } \% \text { motile) }\end{array}$ & $\begin{array}{l}\text { Two frames per } \\
\text { straw ( } \% \text { motile })\end{array}$ \\
\hline 1 & \pm 10.7 & $\pm 9 \cdot 1$ \\
\hline 2 & $\pm 7 \cdot 7$ & \pm 6.5 \\
\hline 3 & $\pm 6 \cdot 3$ & $\pm 5 \cdot 3$ \\
\hline 4 & \pm 5.5 & \pm 4.6 \\
\hline 5 & $\pm 4 \cdot 7$ & $\pm 4 \cdot 1$ \\
\hline
\end{tabular}

* Based on 60 spermatozoa per frame with $50 \%$ motility.

\section{Discussion}

Until recently, objective methods of semen assessment have been mostly a matter for research laboratories. Consequently, much of the equipment in use is rather complex and often inconvenient and expensive (see Katz \& Dott, 1975; Rikmenspoel, 1957). With the increasing sophistication of routine semen processing techniques, the high demand for semen from certain bulls and the requirements of export certification, there is now a need for an objective measurement of the 'recovery rate' of semen which may be easily and reliably applied.

Our method differs from that used by Elliott et al. (1973). We used ordinary microscope slides and coverslips instead of a counting chamber and although this results in some variation in sperm density from one preparation to another and drift may occur more frequently, these were not significant problems in practice. We also dilute the semen less, i.e. $20 \times 10^{6}$ spermatozoa $/ \mathrm{ml}$ instead of $7-10 \times 10^{6} / \mathrm{ml}$, to give densities of $50-100 /$ photograph. To count such numbers without confusion, we used a 1-sec exposure and 400 ASA film, instead of the 2-sec exposures and 125 ASA film used by Elliott et al. (1973). The shorter exposure greatly reduces 'tangling' of tracks and gives a sharper image of non-motile spermatozoa, which are constantly subjected to the 'wake' of motile cells and to Brownian motion. Finally, our use of a citrate buffer enabled us to photograph semen diluted in a milk and egg yolk diluent. Such an opaque medium cannot be used with previously reported techniques for which a volume of citrate equal to or greater than the volume of diluent is required to obtain : 1 clarification.

The statistic we used was the percentage of motile spermatozoa seen on a photographic Provided the photograph has been properly taken, no skill is required to obtain an objective mei of motility. The properties of the statistic are well known and fully documented and therefore any practicable degree of precision may be achieved. The mean of two straws may be expected to give an unbiased estimate of ejaculate motility, distributed like a percentage based on 60 items. Since the variance is inversely proportional to the total number of spermatozoa, a larger field will give a proportionate improvement in precision.

The measurement of semen motility by means of dark-field photomicrography is a very useful technique in the A.I. laboratory. It requires little in the way of specialized equipment, can be quickly mastered by a competent technician, and may be applied for the quality control of frozen semen output, and for research purposes in relation to processing and freezing techniques.

\section{References}

BARTLETT, M.S. (1937) Some examples of statistical methods of research in agriculture and applied biography. J. Roy. Stat. Soc. Suppl., 4, 137-183.
Elliott, F.I., Sherman, J.K., Elliott, E.J. \& Sullivan, J.J. (1973) A photographic method of measuring percentage of progressively motile sperm cells using 
dark field microscopy. Proc. 8th Int. Symp. Zootechny, Milan, pp. 160-168. Italian Ass. for Res. Anim. Sci., Milan.

KATZ, D.F. \& DotT, H.M. (1975) Methods of measuring swimming speed of spermatozoa. J. Reprod. Fert. 45, 263-272.
Rimkmenspoel, R. (1957) Photoelectric and cinematographic measurements of the 'motility' of bull sperm cells. Thesis, University of Utrecht, Netherlands.

Rothschild, LORD (1953) Mammalian Germ Cells. Little, Brown \& Co., Boston.

Received 22 December 1977 